\title{
A CRIAÇÃO DO JARDIM BOTÂNICO DE LONDRINA E ALGUMAS REFLEXỐES SOBRE OS ASPECTOS DA CONSTITUIÇÃO FEDERAL
}

\author{
Gabriel Merlini Tissiano ${ }^{1}$; Carlos Alberto Hirata²; Edinéia Vilanova Grizio Orita ${ }^{3}$ \\ ${ }^{1}$ Mestrando do Programa de Pós-Graduação em Geografia da Universidade Estadual de Londrina, Londrina, PR, gtissiano@gmail.com \\ ${ }^{2}$ Profa ${ }^{a}$ r do Departamento de Geociências da Universidade Estadual de Londrina, Londrina, PR, hiratauel@gmail.com \\ ${ }^{1}$ Prof ${ }^{a}$ Dra do Departamento de Geociências da Universidade Estadual de Londrina, Londrina, PR, edineia@uel.br
}

\section{RESUMO}

Essa pesquisa apresenta discussão sobre o Jardim Botânico de Londrina, a luz de alguns aspectos da Constituição Federal de 1988 que assegura no (art. 225), um "meio ambiente ecologicamente equilibrado" e impõe ao Poder Público o dever de defendê-lo e preservá-lo. Nesse sentido, o Ministério do Meio Ambiente (MMA), juntamente com o Conselho Nacional do Meio Ambiente (CONAMA), normatizou diretrizes através da Resolução CONAMA 339, em 25 de setembro de 2003, estabelecendo que os Jardins Botânicos se configuram como uma Unidade de Conservação - UC, na medida que se caracterizam como um espaço territorial com seus recursos ambientais, incluindo as águas, com características naturais relevantes, legalmente instituído pelo Poder Público, com objetivos de conservação e limites definidos, sob regime especial de administração, ao qual se aplicam garantias de proteção, integrada ao Sistema Nacional de Unidades de Conservação (SNUC), caracterizando sua inauguração iniciada em Dezembro de 2005. O método utilizado nesse trabalho foi pesquisa em bibliografia especializada e na legislação pertinente ao tema, além, de visita in locu e registro fotográfico. Ficou evidente a necessidade de conhecer a legislação, para que essa avance buscando criar dispositivos legais, nos quais os gestores possam se embasar no momento do planejamento e criação dos espaços públicos.

PALAVRAS-CHAVE: Jardim Botânico; Legislação Ambiental; Educação Ambiental

\section{INTRODUÇÃO}

Esse trabalho aborda discussões sobre a Constituição Federal de 1988 assegura a todos, em seu artigo sobre meio ambiente (art. 225), um "meio ambiente ecologicamente equilibrado" e impõe ao Poder Público o dever de defendê-lo e preservá-lo. Um dos instrumentos que a Constituição aponta para o cumprimento desse dever é a "definição de espaços territoriais e seus componentes a serem especialmente protegidos", ou seja, indica que o Poder Público deve criar áreas protegidas e garantir que elas contribuam para a existência de um "meio ambiente ecologicamente equilibrado".

A partir dessas bases legais, por meio da lei no 9.985 de 18 de julho de 2000 cria-se - Sistema Nacional de Unidades de Conservação (SNUC), que define unidade de conservação (UC) como o espaço territorial e seus recursos ambientais, incluindo as águas, com características naturais relevantes, legalmente instituído pelo Poder Público, com objetivos de conservação e limites definidos, sob regime especial de administração, ao qual se aplicam garantias de proteção.

O Ministério do Meio Ambiente (MMA), juntamente com o Conselho Nacional do Meio Ambiente (CONAMA), percebendo a necessidade de normatizar diretrizes para os jardins botânicos brasileiros, vista sua relevância de cunho ambiental, social entre outros, aprova em 25 de setembro de 2003, a Resolução CONAMA 339. Desta forma, a Resolução passa a ser instrumento de uma estratégia de apoio para os jardins botânicos, na medida que os define legalmente numa perspectiva de conservação dos recursos naturais do país, e 
estabelece seus objetivos em consonância com o que é proposto como a missão global dessas instituições pelas Normas Internacionais de Conservação para Jardins Botânicos.

Os Jardins Botânicos e suas funções e seu papel na sociedade evoluíram ao longo do tempo. Conforme Krishnan \& Novy (2016), originalmente estabelecido para estudo de plantas medicinais em meados do século XVI, eles se transformaram em ambientes ativos para introdução, cultivo e divulgação de culturas economicamente importantes durante a Europa expansão das colônias na Ásia, América e África durante os séculos XVII a XIX.

Ainda de acordo com os autores, durante a segunda metade do século $X X$, foi dada importância à necessidade de conservação e uso sustentável da biodiversidade. No século $\mathrm{XXI}$, os Jardins Botânicos são desafiados a abordarem questões que se estendem além das paredes do jardim, colocando a questão social e ambiental como missão.

Estas áreas são um excelente ambiente para se desenvolver diferentes projetos e pesquisas, destacando a relevância da conservação ambiental nas diferentes áreas como educação, biologia, turismo, artes, história, entre outras, possibilitando a divulgação do conhecimento de espécies de plantas (Rocha \& Cavalheiro, 2001).

E nesse aspecto, o Jardim Botânico de Londrina, vem aos poucos ganhando espaço e inserindo instituições educacionais para desenvolver diferentes projetos de pesquisa com o intuito de conservar as espécies.

E nesse contexto, justifica a importância de conhecer a legislação desse espaço público tão importante para a população, tendo como proposta cumprir com as finalidades de um Jardim Botânico, pois entre elas estão, a de promover a pesquisa, a conservação, a educação ambiental e o lazer.

\section{MATERIAIS E MÉTODOS}

A metodologia utilizada foi a revisão de literatura a partir de pesquisas bibliográficas, ou seja, "aquela desenvolvida com base em material já elaborado, constituído principalmente de livros e artigos científicos" (Gil, 2002, p. 44). O referido autor comenta que a principal vantagem da pesquisa bibliográfica reside do fato em permitir ao investigador a cobertura de uma gama de fenômenos muito mais ampla do que aquela que poderia pesquisar diretamente.

A fim de abordar questões cruciais para situar o meio ambiente como uma preocupação global e local, recorreu-se à pesquisa em bibliografia especializada e na legislação pertinente ao tema.

Foram também utilizados, como referência, trabalhos feitos anteriormente envolvendo o uso de metodologias de pesquisa, como levantamento e tratamento de dados. Além, de visita in locu e registro fotográfico.

\section{3}

\section{RESULTADOS E DISCUSSÕES}

Os jardins botânicos brasileiros são considerados unidades de conservação (UC), porém para que houvesse esse tipo de enquadramento legal, foi necessário um longo período de tempo para que a legislação brasileira criasse suas bases legais e um aparato estatal fosse criado.

A Constituição Federal de 1988 assegura a todos, em seu artigo sobre meio ambiente (art. 225), um "meio ambiente ecologicamente equilibrado" e impõe ao Poder Público o dever de defendê-lo e preservá-lo. Um dos instrumentos que a Constituição aponta para o cumprimento desse dever é a "definição de espaços territoriais e seus componentes a serem especialmente protegidos", ou seja, indica que o Poder Público deve criar áreas protegidas e garantir que elas contribuam para a existência de um "meio ambiente ecologicamente equilibrado". 
A partir dessas bases legais, por meio da lei no 9.985 de 18 de julho de 2000 criase o Sistema Nacional de Unidades de Conservação (SNUC), que define unidade de conservação como o espaço territorial e seus recursos ambientais, incluindo as águas, com características naturais relevantes, legalmente instituído pelo Poder Público, com objetivos de conservação e limites definidos, sob regime especial de administração, ao qual se aplicam garantias de proteção.

O SNUC foi concebido de forma a potencializar o papel das UC, de modo que sejam planejadas e administradas de forma integrada com as demais UC, assegurando que amostras significativas e ecologicamente viáveis das diferentes populações, habitats e ecossistemas estejam adequadamente representadas no território nacional. Para isso, o SNUC é gerido pelas três esferas de governo (federal, estadual e municipal).

A aprovação da lei para criação do SNUC foi um processo de aproximadamente 10 anos, no qual vários setores e atores sociais participaram ativamente da sua criação, da qual defendendo seus objetivos próprios. Esta lei reflete um avanço na política ambiental brasileira, ao passo que veio fortalecer a perspectiva de uso sustentável dos recursos naturais, das medidas compensatórias e de uma descentralização mais controlada da política ambiental no Brasil. Nesta perspectiva, Derani (2001) defende a ideia de que o SNUC:

[...] é um sistema no sentido de elaboração racional coordenada. Toma como base de ordenação um conhecimento predominantemente científico. Sendo a ciência elaborações racionais a partir das diversas maneiras de se ver o mundo, pode-se afirmar que o SNUC é uma racionalização do espaço a partir de conhecimentos revelados pela ciência (DERANI, 2001, p. 608).

O SNUC divide as categorias de unidades de conservação federais em dois grandes grupos: proteção integral e uso sustentável. Cada um desses grupos possui diversas categorias de unidades; o grupo de proteção integral é formado por cinco diferentes categorias, sendo elas Estação Ecológica, Reserva Biológica, Parque Nacional, Monumento Natural e Refúgio de Vida Silvestre.

Já no grupo de uso sustentável, as categorias são: Área de Proteção Ambiental, Área de Relevante Interesse Ecológico, Floresta Nacional, Reserva Extrativista, Reserva de Fauna, Reserva de Desenvolvimento Sustentável, Reserva Particular do Patrimônio Natural.

Os jardins botânicos seriam parte de uma nova subdivisão, sendo considerados UC de proteção integral, alguns sob os cuidados dos órgãos ambientais estaduais, como o caso do JB de Londrina, outros federal como o JB do Rio de Janeiro.

Os jardins botânicos são instituições que ao longo de sua história têm contribuído para a conservação da flora e fauna mundial e como não poderia deixar de ser, não apenas acompanham, mas inserem-se ativamente na dinâmica do desenvolvimento das questões relativas ao trato do meio ambiente, conforme afirma Tuxill (1999, p.261):

A maior parte das coleções de espécies silvestres e plantas ornamentais, fora de seu local de origem, se encontra sob custódia dos 1600 jardins botânicos, em todo o mundo. Juntos eles cuidam de representantes de dezenas de milhares de espécies vegetais.

O Ministério do Meio Ambiente (MMA), juntamente com o Conselho Nacional do Meio Ambiente (CONAMA), percebendo a necessidade de normatizar diretrizes para os jardins botânicos brasileiros, vista sua relevância de cunho ambiental, social entre outros, aprova em 25 de setembro de 2003, a Resolução CONAMA 339. 
A construção da Resolução CONAMA 339 foi um processo com longa duração, no qual foi desenvolvido uma forma que a qualifica como um instrumento para o desenvolvimento dos jardins botânicos numa perspectiva conservacionista.

Desta forma, a Resolução passa a ser instrumento de uma estratégia de apoio para os jardins botânicos, na medida que os define legalmente numa perspectiva de conservação dos recursos naturais do país, e estabelece seus objetivos em consonância

com o que é proposto como a missão global dessas instituições pelas Normas Internacionais de Conservação para Jardins Botânicos.

Por meio de iniciativa conjunta do Jardim Botânico do Rio de Janeiro e do Ministério do Meio Ambiente, em 2001 é feita, então, a publicação em Português das Normas Internacionais de Conservação para os Jardins Botânicos, BGCl - (Botanic Gardens Conservation International) (2001), que orienta a ação dos jardins botânicos de todo o mundo pelas diretrizes estabelecidas nos foros internacionais mais atuais.

Dentre os objetivos constantes na resolução, no inciso I do artigo $2^{0}$ é notável a presença da educação ambiental, que deve ser proporcionada pelo jardim botânico. "Art. $2^{\circ}$ Os jardins botânicos terão por objetivo:

I - promover a pesquisa, a conservação, a preservação, a educação ambiental e o lazer compatível com a finalidade de difundir o valor multicultural das plantas e sua utilização sustentável (CONAMA, 2003)

Apesar de a educação ambiental ser uma disciplina relativamente nova, sua importância vem crescendo na mesma proporção em que aumenta a percepção do público quanto à gravidade da perda da biodiversidade. Para que sejam tomadas decisões mais adequadas em relação ao uso dos recursos naturais é preciso que haja uma melhor compreensão dos sistemas ecológicos. Os jardins botânicos desempenham um papel chave na implementação dessas estratégias. Eles não trabalham isolados, mas participam de um movimento, que cresce no mundo inteiro, para tornar a educação ambiental acessível a todos.

Educação ambiental não é simplesmente informar. Se os jardins botânicos se propõem a passar uma mensagem conservacionista, precisam estimular uma mudança nas atitudes e comportamentos. Todos interpretam o mundo a partir de uma estrutura particular de percepção e pensamento. Estes elementos influenciam nossas opiniões e maneira de encarar a vida. Os projetos educativos podem dar oportunidade aos alunos para que avaliem suas atitudes e comportamentos, a partir de uma nova perspectiva.

Dentre os aspectos positivos que a educação ambiental pode proporcionar estão a participar de projetos educativos, no qual os alunos podem precisar adquirir novas habilidades como, por exemplo, habilidades botânicas específicas sobre reprodução, plantio ou identificação. Mas os projetos educativos podem também ajudar crianças e adultos a desenvolver aptidões sociais, tais como colaboração e comunicação. Os educadores precisam definir quais habilidades específicas desejam estimular e desenvolver, sobretudo ao trabalhar com crianças.

Os jardins botânicos serão subdivididos em 3 grupos, conforme artigo 5ำ, que os nomina em A, B e C. De acordo com o Art. $5^{\circ}$ :

O jardim botânico será classificado em três categorias denominadas "A", "B" e "C", observando-se critérios técnicos que levarão em conta a sua infraestrutura, qualificações do corpo técnico e de pesquisadores, objetivos, localização e especialização operacional. (CONAMA, 2003)

Para cada classificação existe uma série de requisitos a serem preenchidos. No caso do Jardim Botânico de Londrina, as exigências contidas na categoria C (Art. 8ํ) não são completamente cumpridas, devido a inexistência de herbário próprio ou associado com 
outra instituição e possuir coleções especiais representativas da flora nativa, em estruturas adequadas, que estariam dispostas nas estufas que estão inacabadas.

Art. $8^{\circ}$ Serão incluídos na categoria "C" os jardins botânicos que atenderem às seguintes exigências:

I - possuir quadro técnico-científico compatível com suas atividades;

II - dispor de serviços de vigilância e jardinagem, próprios ou terceirizados;

III - manter área de produção de mudas, preferencialmente de espécies nativas da flora local;

IV - dispor de apoio administrativo e logístico compatível com as atividades a

serem desenvolvidas;

$\mathrm{V}$ - desenvolver programas de pesquisa visando à conservação das espécies;

VI - possuir coleções especiais representativas da flora nativa, em estruturas adequadas;

VII - desenvolver programas na área de educação ambiental;

VIII - possuir infraestrutura básica para atendimento de visitantes;

IX - ter herbário próprio ou associado com outra instituição;

$X$ - possuir sistema de registro para o seu acervo; e

XI - oferecer apoio técnico, científico e institucional, em cooperação com as unidades de conservação, previstas no Sistema Nacional de Unidades de Conservação da Natureza-SNUC, instituído pela Lei no 9.985, de 18 de julho de 2000. (CONAMA, 2003)

C.

Porém o inciso $1^{\circ}$ possibilita a classificação provisória do JB Londrina na categoria

$\S 1^{\circ}$ Nos casos em que não forem atendidas as exigências para a classificação, prevista nos arts. $6^{\circ}, 7^{\circ}$ e $8^{\circ}$ desta Resolução, o jardim botânico poderá receber registro provisório com enquadramento na categoria $\mathrm{C}$, desde que atenda a, no mínimo, seis das exigências da categoria para a qual requeriu o enquadramento. (CONAMA, 2003)

O desempenho da missão global e o alcance dos objetivos dos jardins botânicos requerem um trabalho conjunto com o maior número de parcerias possíveis: governos, Organizações não governamentais (ONGs), corporações empresariais, comunidades, universidades entre outros. Pois, além de ser um campo amplo para a pesquisa o Jardim Botânico é um atrativo turístico que pode atrair turistas para a cidade e movimentar a economia regional.

A cidade de Londrina é contemplada por vários espaços públicos direcionados a educação ambiental, como o Parque Municipal Arthur Thomas, Parque ecológico Dr. Daisaku Ikeda entre outros. O Jardim Botânico de Londrina também é um desses espaços. Situado na Avenida dos Expedicionários, s/n, o seu acesso é por meio da Rodovia PR 445, próximo ao Instituto Agronômico do Paraná (IAPAR). Destaca-se a localização privilegiada do empreendimento, pois situa-se próximo às vias de acesso rápido e está integrado a mancha urbana, facilitando a chegada dos visitantes (Figura 1). 


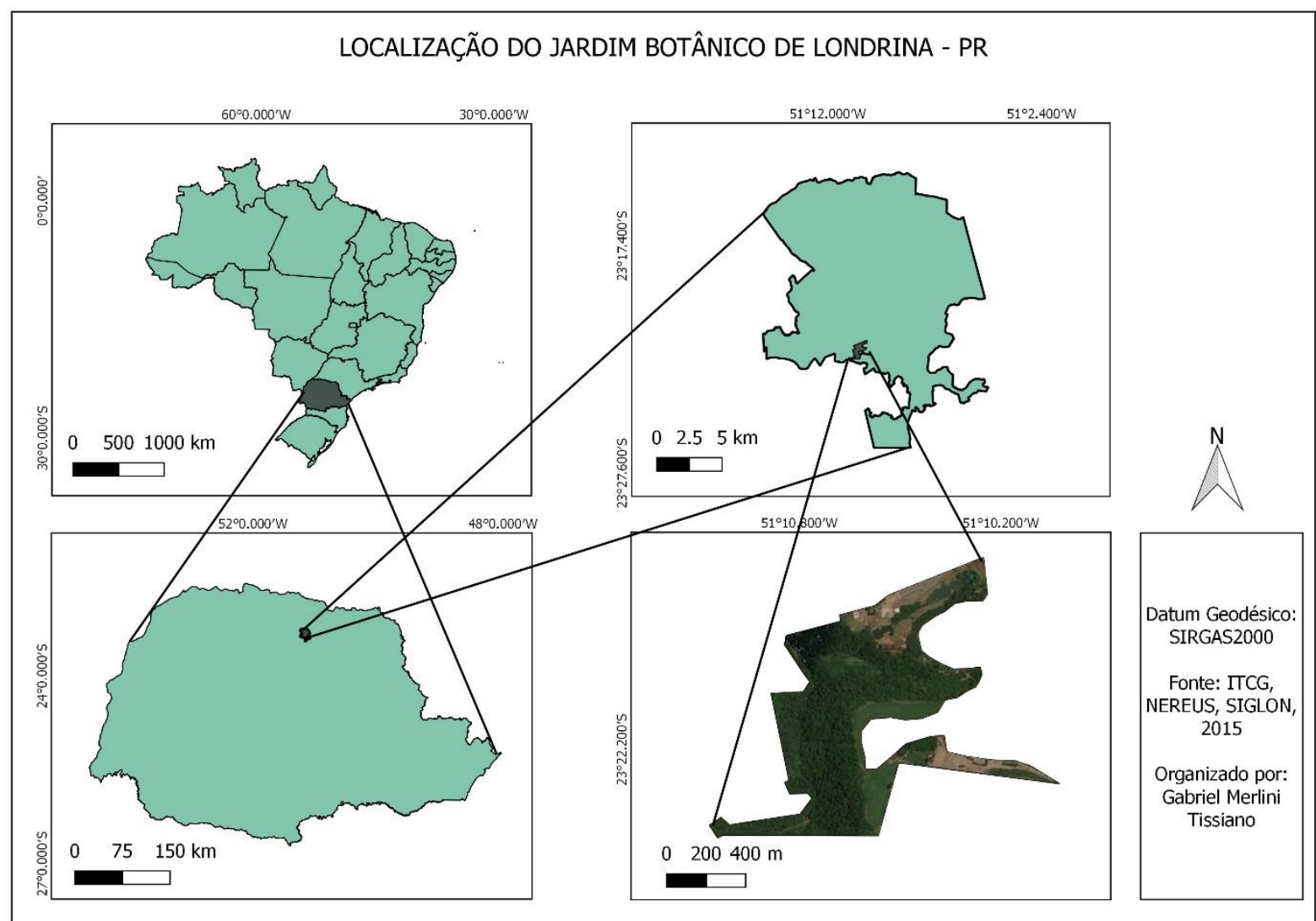

Figura 1: Localização do Jardim Botânico de Londrina. Fonte: ITCG, NEREUS, SIGLON 2015.

Em 1994, foi lançado na revista FOLIO uma matéria a respeito do desejo de construir o Jardim Botânico de Londrina. O local escolhido era no Patrimônio Regina, porém não se obteve êxito devido a troca do governo estadual. Reuniões foram feitas para debater e decidir o melhor lugar e as maneiras para desenvolver o Jardim Botânico.

Vários locais foram oferecidos a Secretaria de Estado do Meio ambiente e Recursos Hídricos -SEMA a época para a construção, mas que necessitavam de recursos financeiros para desapropriação para pagamento, porém através de uma ação demandada pelo Secretário Luiz Eduardo Cheida, ao Coordenador de Gestão Territorial da SEMA Geógrafo Carlos Alberto Hirata, este juntamente com o Diretor Geral Hélio Dutra de Souza e o Coordenador de Biodiversidade e Floresta, Biólogo Ricardo Ramirez, definiram o local e iniciaram assim, as tratativas com os doadores das áreas do Jardim Botânico de Londrina, desonerando o Estado e a sociedade de ônus pelo pagamento da terra devido o interesse público da natureza do projeto.

Inicialmente, as tratativas ocorreram com o conselho de administração do Instituto Agronômico do Paraná - IAPAR, para viabilização inicial de instalação da área do projeto, pois necessitaria da cessão de 70 hectares, localizada junto a divisa da face sul da área da sede até o ribeirão cafezal e que também serviria de área de regularização da reserva legal da propriedade e de áreas de preservação permanente.

O valor inicial da obra foi utilizado de recursos do Fundo Estadual do Meio ambiente, oriundos de multa aplicada pelo Instituto Ambiental do Paraná-IAP oriundos de vazamento de óleo diesel do Pool de combustível de Londrina no córrego Lindoia. Posteriormente recebeu outros recursos na fase implementação de projetos educacionais da Duke Energy Brazil, empresa multinacional estadunidense que opera usinas geradoras de energia, que viabilizou um programa de educação ambiental composto 
por trilha ecológica e vídeo educativo. Algumas estruturas que foram previstas para serem construídas, não foram concluídas até o presente momento.

O projeto do Jardim Botânico foi elaborado pelo Arquiteto Orlando Bussarelo, tomando como base um estudo de quesitos feito por uma equipe de colaboradores coordenado pelo professor Agnaldo Kupper, que recebeu importantes contribuições de docentes de universidades londrinenses, que estabelecia a necessidade da área contemplar reserva nativa, terrenos planos e elevados e boa oferta de águas superficiais. Como resultado, a espacialização do Jardim Botânico foi dividida em setores, dentre eles a área administrativa, a de recreação infantil, 10 espelhos d’água, três estufas, teatro ao ar livre, herbareo, arboretos, insetário, jardins temáticos, mirante, centro de pesquisa, viveiro de mudas, ciclovia e pista de caminhada.

De acordo com Bussarello et al. (2005/2006) o primeiro setor possuiria o estacionamento para 200 visitantes, praça de acesso e portal, administração, centro de apoio e recepção ao visitante, (que possuiria auditório, salas de reunião, sanitários, decks, restaurante, livraria e exposições circulares). No segundo setor possuiria anfiteatro a céu aberto, com palco, arquibancada para 960 pessoas, sanitários e torres para sonorização. No terceiro setor seria formado pelas estufas permanentes, dança das águas, jardim Burle Marx e lago 2. Já no quarto setor seria localizado o insetário/borboletário com $2.800,00$ m², quiosque para piquenique e arboreto de palmáceas.

Ainda de acordo com autor no quinto setor seria localizado os jardins temáticos, com praça, mirante e quiosques pergolados para descanso. O sexto setor seria formado pelo herbarium, museu, biblioteca, centro de pesquisas, escola de jardinagem e acesso e estacionamento para funcionários. Com $213.610,00 \mathrm{~m}^{2} \mathrm{o}$ arboreto faria parte do setor 7 e 0 oitavo setor seria formado por viveiros, centro de produção de mudas, pátio de carga e descarga, estacionamento para máquinas e tratores e o terceiro lago.

Os jardins temáticos foram projetados para representar as formas, as cores, as estruturas da vegetação e jardins representativos de países, etnias e ecossistemas de ambientes exóticos. A praça Burle Marx (Figura 2) foi projetada para homenagear o maior paisagista brasileiro do século $X X$, com utilização de espécies vegetais que levam seu nome. Nesta praça foi projetado um conjunto de fontes interativas, permitindo aos visitantes brincarem e se refrescarem com água. 


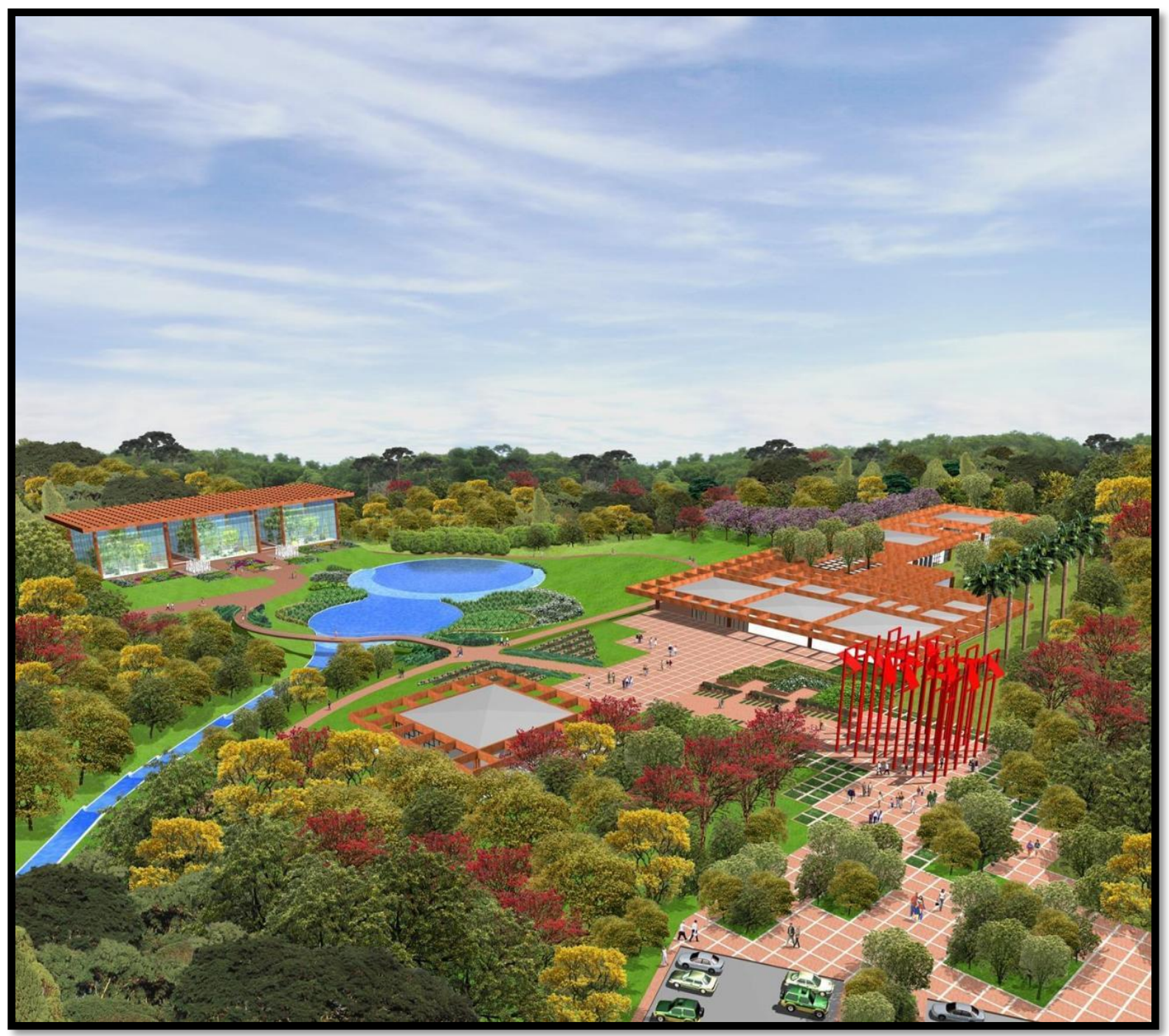

Figura 2: Imagem do projeto inicial do Jardim Botânico de Londrina.

Fonte: SEMA/PR 2005.

As estufas, foram pensadas para colecionar bromélias epífitas, orquídeas e espécies exóticas aclimatadas em ambientes especiais. Os lagos foram construídos sobre base existente no local com água de nascentes que formam espelhos d'água e um conjunto de pequenas cachoeiras de 1 metro de altura. Existe também uma pista de caminhada e ciclovias para a prática de exercícios físicos.

É possível realizar uma comparação das instalações que ainda não foram implantadas por meio da visualização da figura 3, que representa o projeto inicial do Jardim Botânico. A praça Burle Marx, estufa, arboretos e jardins temáticos estão inacabados. Outras partes ainda não começaram a ser construídas. Questionada sobre a finalização do projeto inicial, a diretoria do Jardim Botânico disse que aguarda repasse de verba do governo estadual, porém não há previsão para ocorrer.

Foi cedido a força verde um espaço do Jardim Botânico, no qual eles criaram sua base de operações, inviabilizando dessa forma a execução do projeto inicial, que previa a utilização de praticamente todo território. 


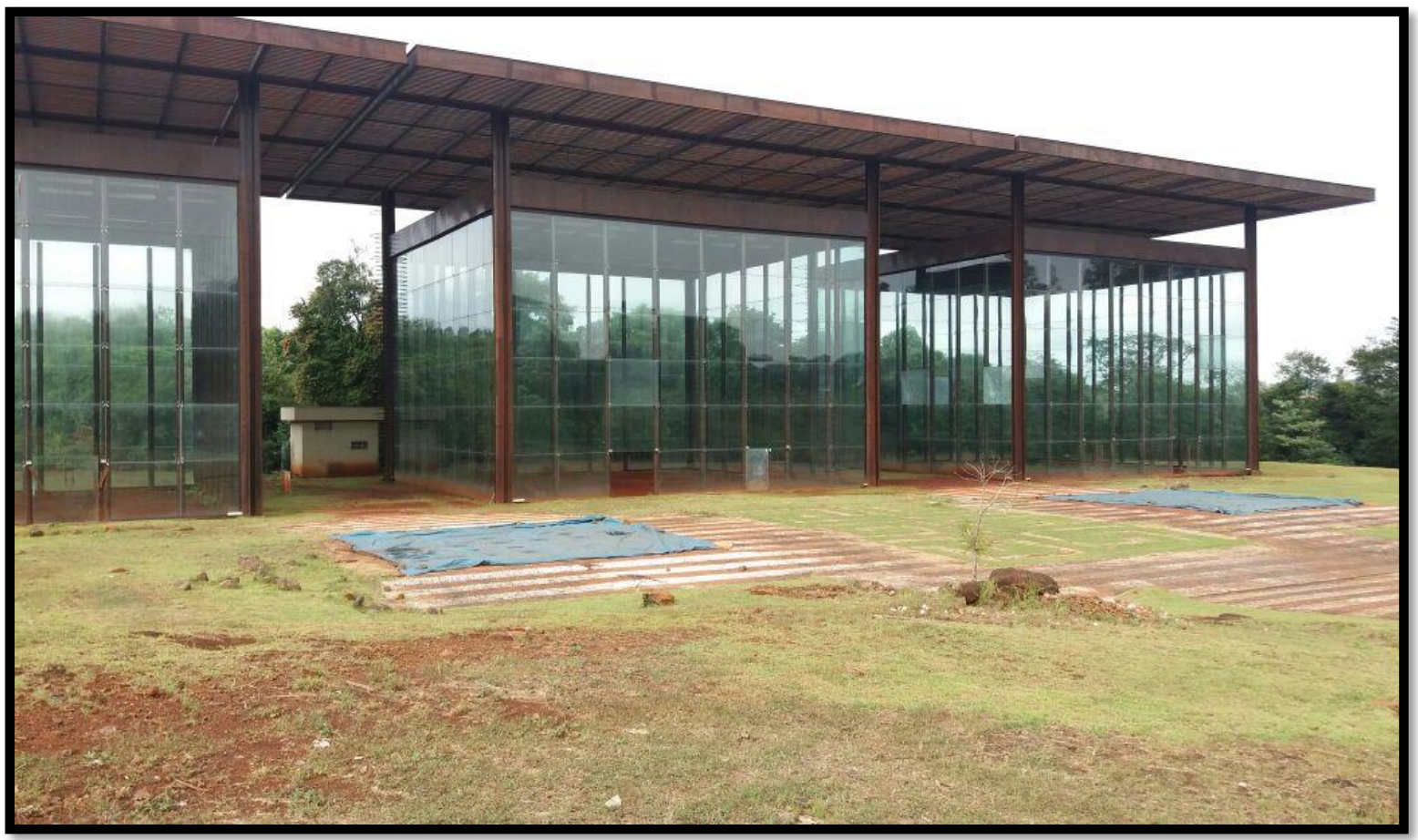

Figura 3: Estufa inacabada e praça Burle Marx do Jardim Botânico de Londrina.

Fonte: TISSIANO, G. M., 2018.

Localizado no município de Londrina e inserido na bacia hidrográfica do Ribeirão Cafezal, com mais de 1 milhão de metros quadrados de mata nativa, nascentes, rios, ribeirões e córregos, conforme figura 4, cria-se o Jardim Botânico de Londrina, por meio do Decreto no 6.184 de 8 de março de 2006. O órgão governamental responsável pela construção é a Secretaria de Estado do Meio Ambiente e Recursos Hídricos - SEMA/PR. Em janeiro de 2007, através do Decreto no 45, foi declarado de utilidade pública para fins ambientais. 


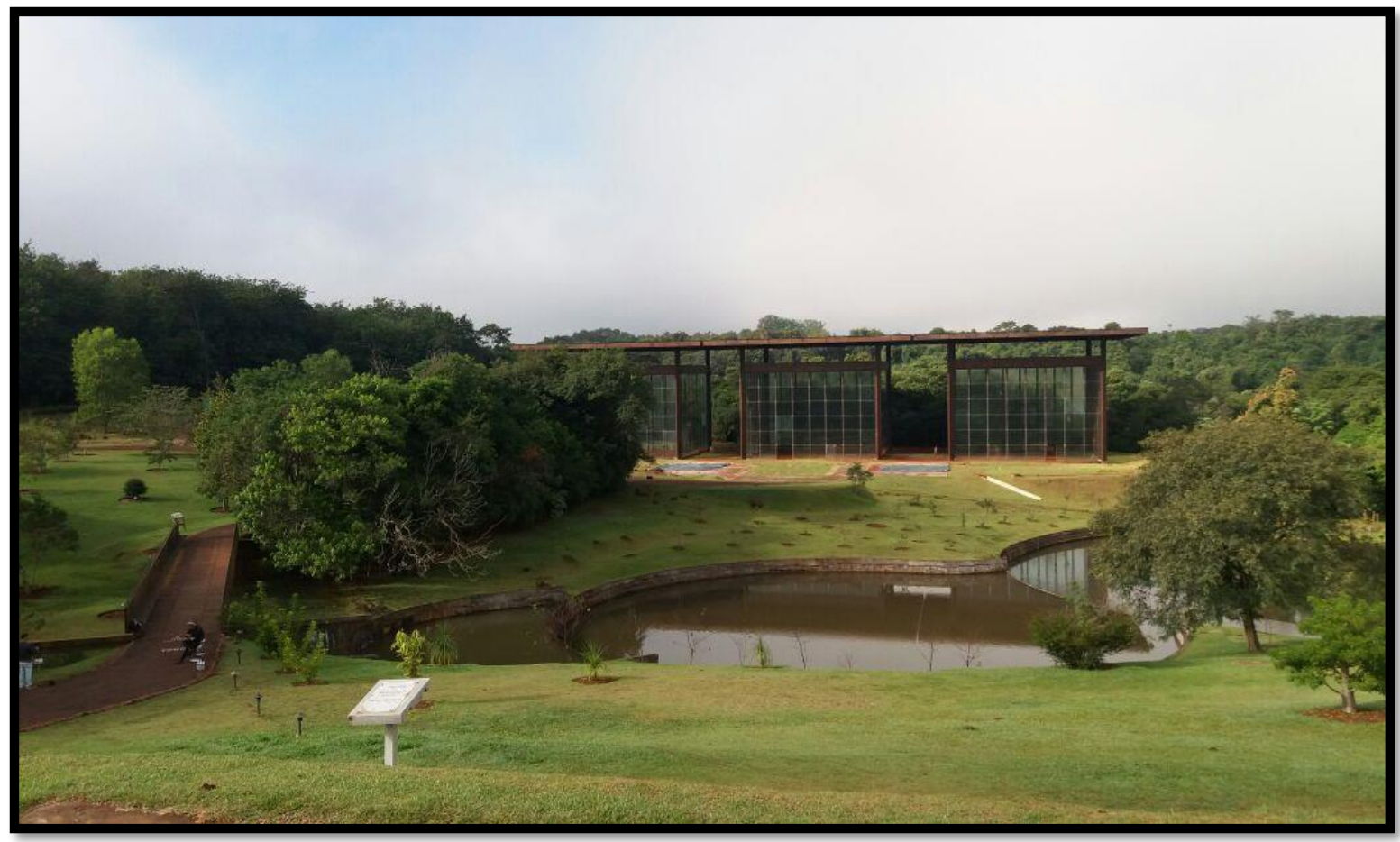

Figura 4: Vista parcial do Jardim Botânico de Londrina.

Fonte: TISSIANO, G. M., 2018.

Um dos intuitos da criação do Jardim Botânico é a promoção de pesquisas, a conservação e a preservação da natureza a partir de coleções de plantas vivas e cientificamente reconhecidas. A oferta de lazer para a população e a educação ambiental foi outro ponto pensado, pois é de extrema importância o equilíbrio entre homem e natureza.

O Jardim Botânico de Londrina representa um local de extrema importância para a população, pois nele são oferecidos lazer, um espaço verde dentro da cidade cinza e cheia de concreto armado. O local pode ser utilizado como sala de aula, visando a interação do aluno com o meio e a visualização na prática de conceitos vistos na sala de aula.

\section{CONCLUSÃO}

Os jardins botânicos são dotados de objetivos e finalidades de extremo valor para a sociedade na qual ele está inserido, devido ao seu potencial papel de desenvolver agentes transformadores, que observam a multiplicidade das relações entre o espaço socialmente produzido e o natural, buscando o equilíbrio entre eles.

A legislação avança buscando criar dispositivos legais, nos quais os gestores públicos possam se embasar no momento do planejamento e criação dos espaços públicos, pois esse tem o dever de defendê-lo e conservá-lo, tendo dessa forma, o meio ambiente ecologicamente equilibrado.

As finalidades e objetivos propostos para um jardim botânico são importantes para a população em geral, sendo notório que o Jardim Botânico de Londrina cumpre um papel fundamental para a compreensão pública no que se refere a conservação e educação ambiental. $\mathrm{O}$ que vem de encontro com as finalidades de um Jardim Botânico, pois entre elas estão, a de promover a pesquisa, a conservação, a educação ambiental e o lazer.

\section{REFERÊNCIAS}

Botanic Gardens Conservation International et al. 2001. Normas Internacionais de Conservação para Jardins Botânicos. Rio de Janeiro, 109 p. 
BRASIL. Constituição (1988). Constituição (da) República Federativa do Brasil. Brasília: Senado Federal, 1988. "Art. 225. Todos têm direito ao meio ambiente ecologicamente equilibrado, bem de uso comum do povo e essencial à sadia qualidade de vida, impondose ao Poder Público e à coletividade o dever de defendê-lo e preservá-lo para as presentes e futuras gerações". Disponível em: <http://www.planalto.gov.br>. Acesso em 19 dez. 2018

BRASIL. Lei №. 339, de 25 de setembro de 2003. Dispõe sobre a criação, normatização e o funcionamento dos jardins botânicos, e dá outras providências. Disponível em: <http://www.icmbio.gov.br>. Acesso em 20 dez. 2018.

BUSARELLO, O; BUSARELLO, D. C. S.; BUSARELLO, D. S. Jardim Botânico de Londrina Anteprojeto. 2005/2006.

DERANI, C. A estrutura do Sistema Nacional de Unidades de Conservação - Lei no 9.985/2000. Revista de Direitos Difusos, ano I, v. 5, p. 607-616, 2001.

KRISHNAN, S.; NOVY, A. The role of botanic gardens in the twenty-first century. CAB Reviews 11, n. 023. 2016.

GIL, A. C. Como elaborar projetos de pesquisa. 4. ed. São Paulo: Atlas, 2002.

ROCHA, Y. T.; CAVALHEIRO, F. Aspectos históricos do Jardim Botânico de São Paulo. Revista Brasileira de Botânica 24: 15. 2001. 